\section{Aortico left ventricular tunnel and bicuspid aortic valve with severe stenosis: a rare combination}

Aortico left ventricular tunnel (ALVT) is a rare, abnormal paravalvular communication between the aorta and the left ventricle. ${ }^{1}$ After the first description by Edwards in 1961, approximately 130 cases have been reported in the literature.
However, there are only a few reports of ALVT associated with severely stenotic bicuspid aortic valve. ${ }^{2}$

The aetiology of aortico-ventricular tunnel is unknown. The formation of the tract is considered as a consequence of primary separation of the aortic annulus from the fibrous skeleton of the heart. The failure of normal development of the tissue plane between the facing aortic and pulmonary sinuses is another proposed mechanism. Other hypotheses include an abnormal coronary artery, the early or intrauterine rupture of a sinus of Valsalva aneurysm, malformation of the distal bulbus cordis or the persistence of embryonic remnants of the 5th aortic arch. Hovaguimian and colleagues ${ }^{3}$ defined four anatomic types of ALVT: a slit-like opening at the aortic end in type 1, a large extracardiac aneurysm in type 2 , an intracardiac aneurysm of

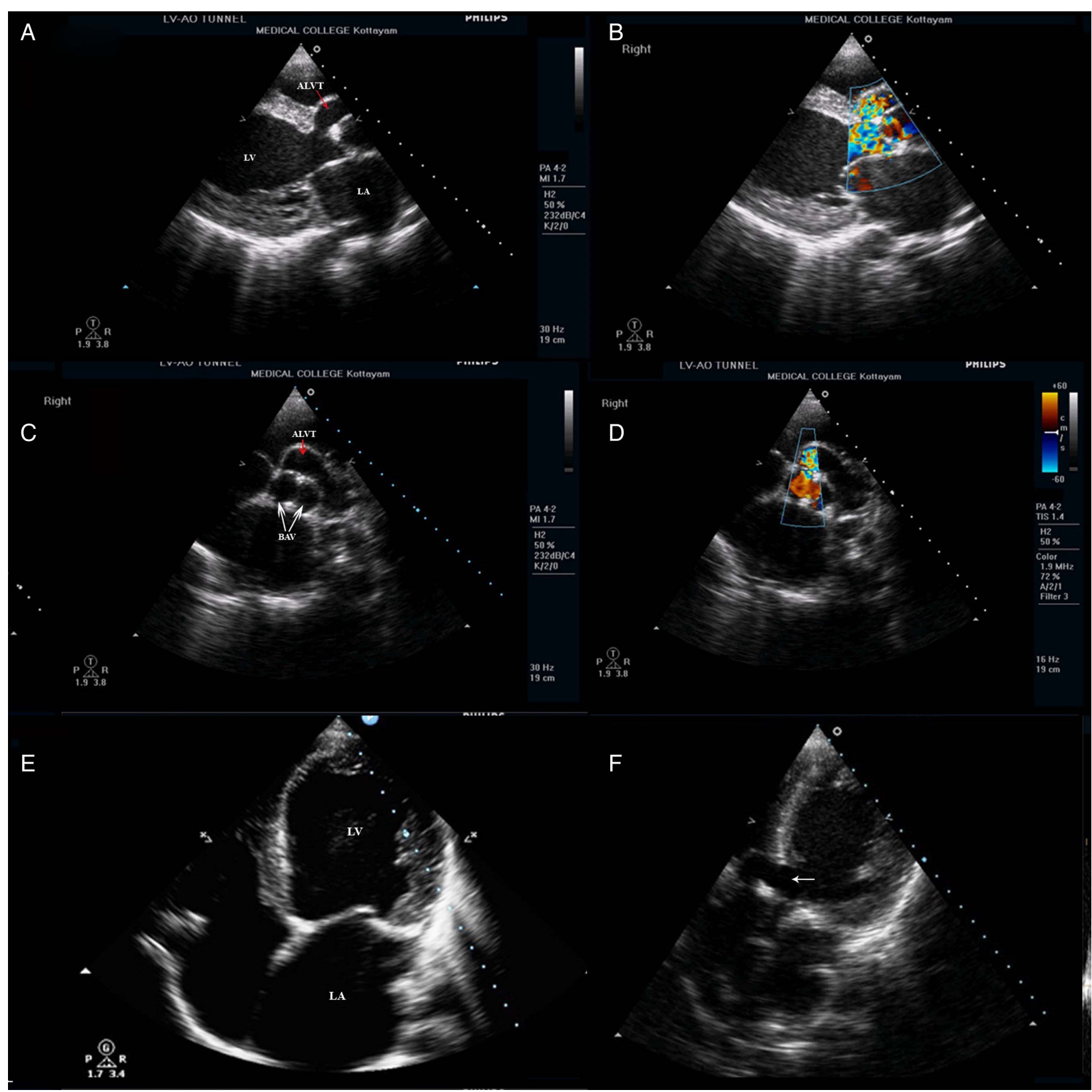

Figure 1 Echocardiographic images. (A) Parasternal long axis view showing the opening of the tunnel into the left ventricle. (B) Colour Doppler showing severe regurgitation through the tunnel. (C) Parasternal short axis view showing the aortico left ventricular tunnel (ALVT) (red arrow) and bicuspid aortic valve (white arrows). (D) Parasternal short axis view showing the aortic end of the tunnel and the flow from the aorta into the ALVT. (E) Apical 4 chamber view showing the dilated left atrium and left ventricle. (F) Apical 5 chamber view showing the opening of the tunnel into the left ventricle (white arrow). 
A

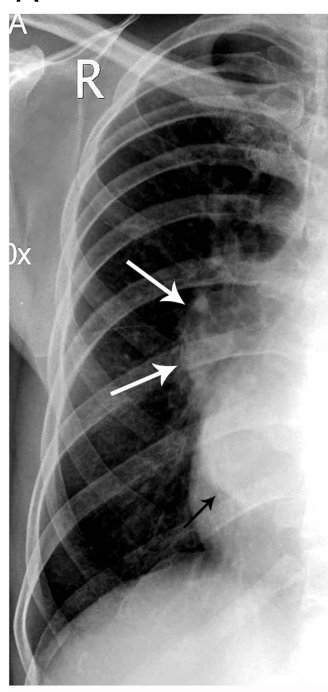

B

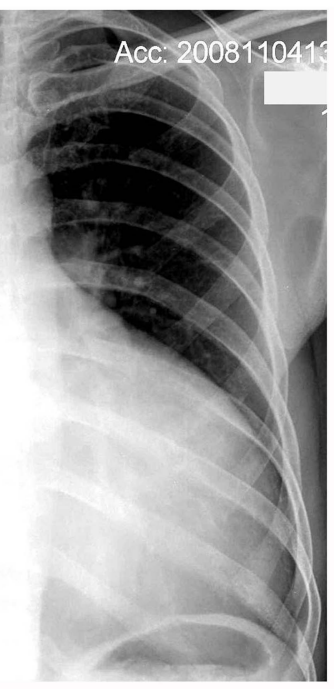

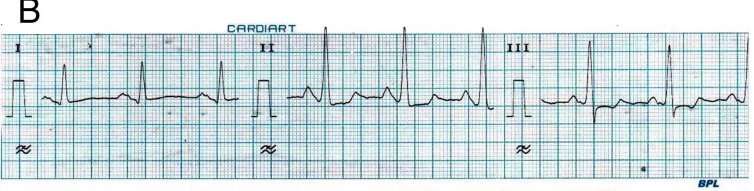
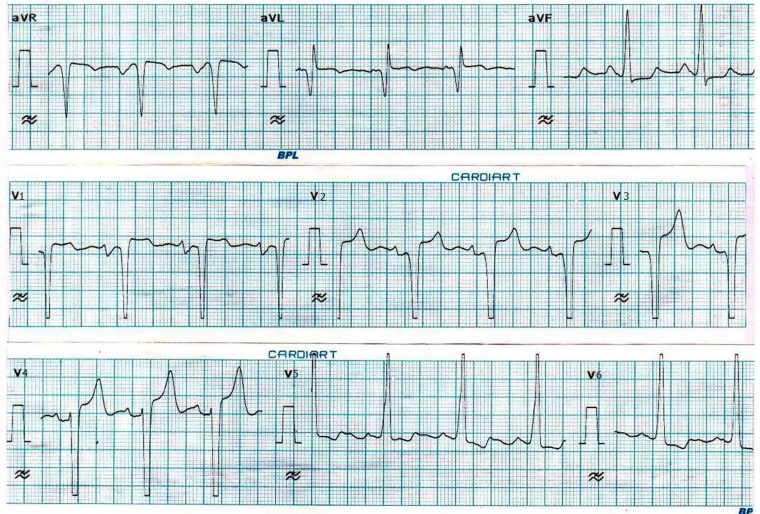
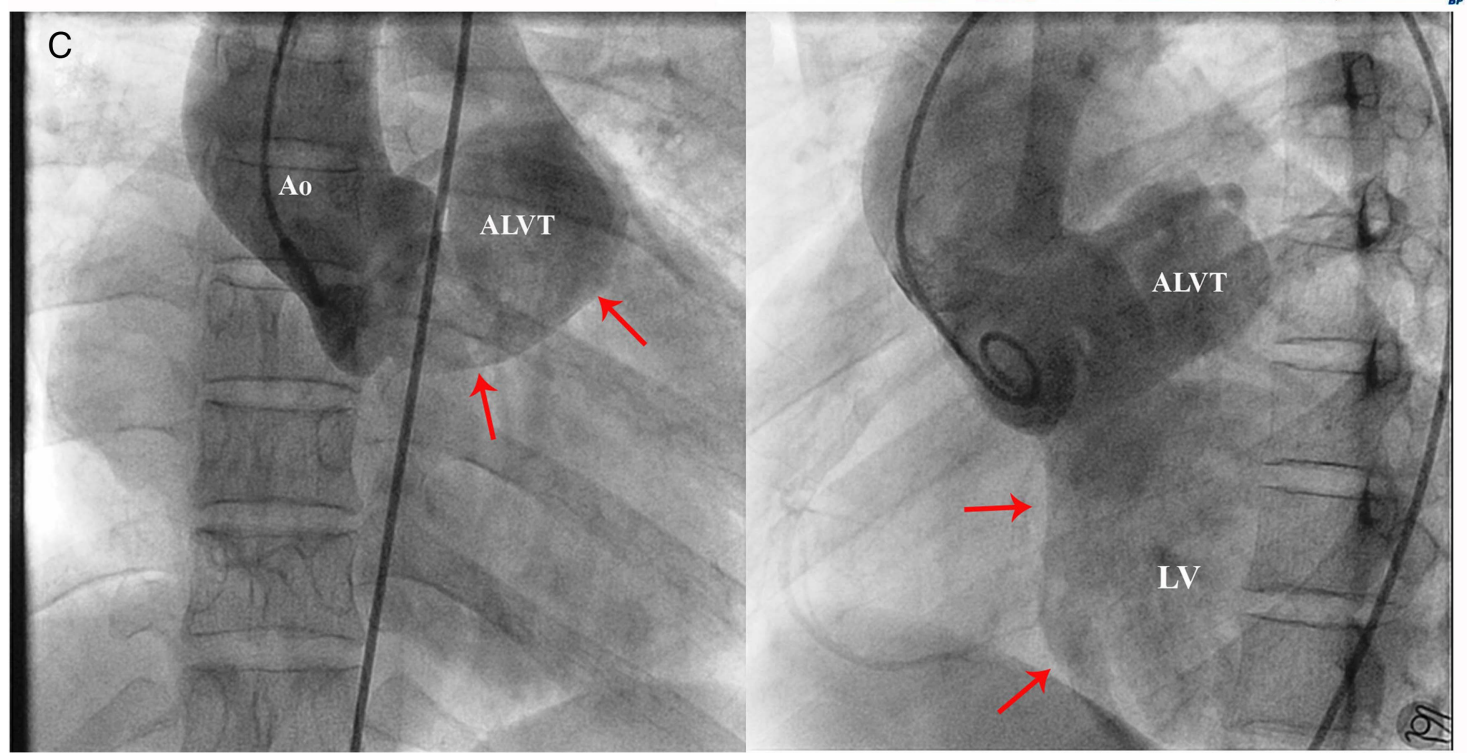

Figure 2 (A) Chest X-ray showing right paracardiac opacity casted by the dilated ascending aorta and right pulmonary artery (white arrows) and dilated left atrium (black arrow). (B) ECG showing left ventricular hypertrophy with strain pattern. (C) Aortic root angiogram in antero posterior (AP) and left anterior oblique (LAO) views showing the aortico left ventricular tunnel (ALVT) and severe regurgitation through the tunnel, with opacification of left ventricle by the contrast (red arrows).

the septal portion of the tunnel in type 3 and a combination of types 2 and 3 in type 4 . We report the case of an adult man with Type II ALVT with associated bicuspid aortic valve and severe aortic stenosis, which was successfully treated by surgery. The case is unique as there are no reports of ALVT or its rare combination with stenotic bicuspid aortic valve in this age group. $^{2}$

Thirty-eight-year-old man presented with symptoms and signs of congestive cardiac failure and a systolo-diastolic murmur (see online supplementary audio clip 1) along the left sternal border. Transthoracic echocardiography revealed a Type II ALVT with severe aortic regurgitation through the tunnel into the left ventricle (figure $1 \mathrm{~A}-\mathrm{F}$, online supplementary videos 1 and 2 ). There was associated bicuspid aortic valve with severe aortic stenosis and a peak systolic gradient and a mean transvalvular gradient of 74 and $48 \mathrm{~mm} \mathrm{Hg}$, respectively (figure 1C, online supplementary figure S3A and video 3). The findings were confirmed in the transesophageal echocardiography (see online supplementary figure S3B). Chest X-ray showed cardiomegaly and left atrial enlargement (figure 2A). ECG showed left ventricular hypertrophy with strain pattern (figure 2B). Aortic root angiogram (figure 2C, online supplementary videos 4 and 5) clearly demonstrated the tunnel and the severe regurgitation into the left ventricle through the tunnel. Patient underwent successful patch closure of the tunnel with aortic valve replacement, with an uneventful postoperative recovery.

\section{K Jayaprakash, ${ }^{1}$ Gailin Bronson Sebastian, ${ }^{2}$ Raju George ${ }^{1}$}

${ }^{1}$ Department of Cardiology, Government Medical College, Kottayam, Kerala, India ${ }^{2}$ Department of Cardiology, Pariyaram Medical College, Kannur, Kerala, India

Correspondence to Dr K Jayaprakash, Department of Cardiology, Government Medical College, Kottayam 686008, Kerala, India; jayaprakashkpillai@gmail.com

Competing interests None declared.

Patient consent Obtained. 
Provenance and peer review Not commissioned; externally peer reviewed.

Heart Asia 2015;7:41-43. doi:10.1136/heartasia-2015-010609

Additional material is available. To view please visit the journal (http://dx.doi.org/ 10.1136/heartasia-2015-010609).

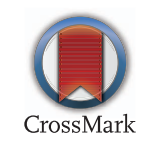

To cite Jayaprakash K, Sebastian GB, George R. Heart Asia 2015;7:41-43. doi:10.1136/heartasia-2015-010609

\section{REFERENCES}

1 Levy MJ, Lillehei CW, Anderson RC, et al. Aortico-left ventricular tunnel. Circulation $1963 ; 27: 841-53$.

2 Martins JD, Sherwood MC, Mayer JE Jr, et al. Aortico-left ventricular tunnel: 35 year experience. J Am Coll Cardiol 2004:44:446-50.

3 Hovaguimian H, Cobanoglu A, Starr A. Aortico-left ventricular tunnel: a clinical review and new surgical classification. Ann Thorac Surg 1988;45:106-12. 